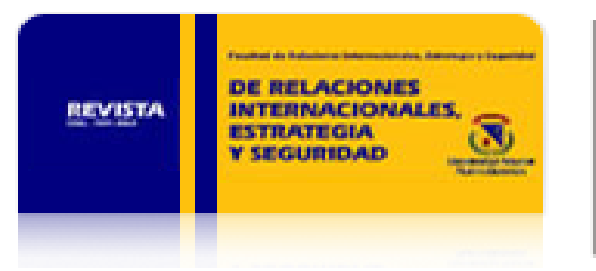

Revista de Relaciones Internacionales, Estrategia y Seguridad

ISSN: 1909-3063

cinuv.relinternal@unimilitar.edu.co

Universidad Militar Nueva Granada

Colombia

Rojas, Héctor

Confucio: Padre de la nación más antigua del mundo

Revista de Relaciones Internacionales, Estrategia y Seguridad, vol. 2, núm. 2, julio-diciembre, 2007

Universidad Militar Nueva Granada

Bogotá, Colombia

Disponible en: http://www.redalyc.org/articulo.oa?id=92720205

- Cómo citar el artículo

- Número completo

- Más información del artículo

- Página de la revista en redalyc.org

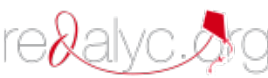

Sistema de Información Científica

Red de Revistas Científicas de América Latina, el Caribe, España y Portugal

Proyecto académico sin fines de lucro, desarrollado bajo la iniciativa de acceso abierto 
rev.relac.int.estrateg.segur.2(2):189-205,2007

\section{CONFUCIO: Padre de la nación más antigua del mundo}

Héctor Rojas. ${ }^{1}$

\section{RESUMEN}

A continuación se presentará un desarrollo teórico conceptual del nacionalismo y el perennialismo, para continuar con algunos de los aportes de Confucio al pensamiento colectivo a partir de sus enseñanzas y finalmente intentar evidenciar que la producción intelectual de Confucio permeó las fibras de la sociedad China al punto de continuar siendo replicadas en la actualidad. En ese sentido, podría considerarse a Confucio como el padre, o por lo menos, un personaje ampliamente influyente en la actual situación de la Nación China.

Palabras Claves: Confucio, Perennialismo, Nacionalismo, China, Cultura, Analectas, Mentalidad Colectiva

\footnotetext{
${ }^{1}$ Profesional en Finanzas y Relaciones Internacionales (Universidad Externado de Colombia), Magíster en DesarroIlo Económico en América Latina (Universidad Internacional de Andalucía-España), Especialista en Estudios Políticos (Universidad Sergio Arboleda), en curso Master en Science Politique et Relations Internationales ou Monde Contemporaine (Université de Marne -La-Vallée-Francia), Consultor Internacional y Docente Universitario. hectorojas@hotmail.com
} 


\begin{abstract}
It will present a conceptual and theorycal development about nationalism and the perennialism, to continue with some Confucius's lessons to the collective thought using his lessons and finally to try to make evident that Confucius's intellectual production get influence the fibres of the Chinese society, until the point to exist in the actuality. In that sense, it could possible to consider Confucius as the father or at least a very influent personage in the actual China's Nation situation.
\end{abstract}

Key Words: Confucius, Perennalism, Nationalism, China, Culture, Analectas, Collective Mentality

A pesar de que el concepto de nacionalismo es posterior a la existencia de Confucio (551-479 A.C), ya que se reconoce con sentido político-social por primera vez usado por Gottfried Herder o el Abad Agustín de Barruel, a fines del S. XVIII (SMITH, 2004:19); en la China moderna, se pueden percibir elementos confucionistas que han trascendido en la historia y hacen su aporte al pensamiento colectivo. De la misma manera se considera que para el caso Chino, aun cuando la ideología nacionalista fuera reciente, siempre ha existido el concepto de nación lo que lleva a reconocer el perennialismo como forma de entender el nacionalismo en esta cultura milenaria.

\title{
NACIONALISMO
}

De acuerdo con Edgar Morin, "El Estado-nación es un ser social o sociedad. Es una sociedad territorialmente organizada que asocia las nociones de Gemeinschaft o comunidad, y de Gesellschaft o sociedad. La nación es una sociedad en sus relaciones de interés, de competiciones, rivalidades, ambiciones, conflictos sociales y políticos. Pero es igualmente una comunidad identitaria, una comunidad de actitudes y una comunidad de reacciones frente al extranjero y sobre todo al enemigo" (MORIN, 1993: 451-458).

La Nación es más que una comunidad de personas de un mismo origen étnico y racial, y que generalmente hablan un mismo idioma, que tienen una tradición, historia y orígenes comunes que los llevan a desarrollar un sentimiento de identidad común. "Las naciones hacen al hombre; las naciones son las constructoras de las convicciones, fidelidades y solidaridades de los hombres. Una simple categoría de individuos llegan a ser una nación si y cuando los miembros de la categoría se reconocen mutua y firmemente ciertos deberes y derechos en virtud de su común calidad de miembros. Es ese reconocimiento del prójimo como individuo de su clase 
lo que los convierte en nación, y no los demás atributos comunes, cualesquiera que puedan ser, que distinguen a esa categoría de los no miembros de ella."(GELLNER, 1994: 20)

Para el caso de China a partir de una interpretación de las propuestas de MORIN, se podría pensar en la concepción de "comunidad de destino" en la medida en que la comunidad es de carácter cultural-histórico. Es cultural por los valores, costumbres, ritos, normas, creencias comunes; es histórica por los avatares y pruebas soportadas en el curso del tiempo. Es, según la expresión de Otto Bauer, una comunidad de destino. Este destino común es memorizado, transmitido de generación, por la familia, los cantos, las músicas, las danzas, las poesías y los libros, y, a continuación por la escuela, que integra el pasado nacional en el espíritu de los niños, en el que resucitan los sufrimientos, los lutos, las victorias, las glorias de la historia nacional, los martirios y hazañas de sus héroes. Así, identificarse con el pasado hace presente la comunidad de destino (MORIN, 1993: 451-458).

\section{PERENNIALISMO}

En el marco del estudio del nacionalismo se encuentran el paradigma modernista, que es el más reconocido a partir de la segunda guerra mundial, el perennialismo, que se desarrollará un poco más y el etnisimbolismo que podría ser considerado como el enfoque postmodernista.

Antes de la segunda guerra mundial se pensaba que a pesar de que el concepto de nacionalismo fuera reciente, siempre habían existido naciones en cada período histórico, y que muchas naciones existían desde tiempo inmemorial, es a esta concepción del nacionalismo a la que se llama perennialismo.

El perennialismo se alimenta también de la idea de evolución social, con su énfasis en el gradualismo, las etapas del progreso y la acumulación social y cultural. También puede entenderse a partir de la idea de que las naciones son comunidades naturales, pero sin confundir la idea con una concepción naturalista de la nación que es la idea del "primordialismo".

Lo que necesita el perennialismo es una creencia basada en algún tipo de observación empírica de que las naciones han existido durante un largo período de tiempo. En ese sentido, la concepción de "perennialismo continuo" reconoce que las naciones tienen una historia continua y larga pudiéndose rastrear sus orígenes hasta la edad media o incluso en algunas ocasiones hasta la antigüedad, como es el caso de China. El énfasis esta dado a partir de la continuidad y longevidad nacional.

Por otro lado se encuentra el "perennialismo recurrente", afirmando que las naciones concretas son históricas; cambian con el tiempo. Como menciona RENAN “ tienen un origen y tendrán 
un final", pero la nación como categoría de asociación humana, es eterna y ubicua, que reaparece en cada período de la historia y se encuentra en cualquier continente del planeta. Aquí nos hallamos ante una recurrencia del mismo tipo de identidad cultural colectiva, aun cuando pueda expresarse de formas diferentes en distintos momentos de la historia. Aunque las naciones concretas aparezcan y desaparezcan, la idea de nación es un fenómeno universal u autónomo, y como tal puede aplicarse a muchas comunidades culturales o políticas en cualquier época histórica y en cualquier lugar (RENAN, 1882)

De acuerdo con las características de China, el paradigma perennialista es el que mejor enmarca el concepto de nacionalismo Chino, aunque vale resaltar que el perennialismo tiene su punto de apoyo en la historia antes que en la teoría, por lo cual los resultados de las interpretaciones pueden Ilegar a ser reduccionistas. ${ }^{2}$

A pesar de la dificultad de otorgar valores absolutos a las interpretaciones de Nación, se debe rescatar el carácter místico, mitológico y lleno de simbolismos y aún de superstición que presenta la Nación China, el Dragón Celeste, la Tradición, el Imperio del Medio, el entorno mágico que enmarca el nacimiento de Confucio, el poder centralizado en los diferentes emperadores, en Sun Yat Sen, Mao o Deng Xiaoping, hacen que la interpretación del carácter nacionalista chino, responda a un escenario conservador respetuoso de los ritos y las costumbres, los ancestros y los ídolos, cercano a la concepción perennialista en donde la nación China ha existido y existirá siempre.

\footnotetext{
2 Para efectos de este ensayo entiéndase "nacionalismo" como: HOBSBAWM, p. 17. "Utilizó el término nacionalismo en el sentido en que lo definió GELLNER, a saber: para referirme básicamente a un principio que afirma que la unidad política y la nacional debería ser congruente."

SMITH, p. 67. "El nacionalismo es un movimiento ideológico para lograr y mantener la autonomía, unidad e identidad en nombre de un grupo humano que según algunos componentes constituye de hecho o en potencia una nación." Entiéndase "Estado" como: GELLNER, Naciones y Nacionalismos, p 16. "El estado es la especialización y concentración del mantenimiento del orden. El estado es aquella institución o conjunto de instituciones específicamente relacionadas con la conservación del orden (aquellas pueden estar relacionadas con muchas mas cosas)." "No todas las sociedades están provistas de un estado. De ello se sigue inmediatamente que el problema del nacionalismo no surge en sociedades desestatizadas. Si no hay estado, nadie, evidentemente, puede plantearse si sus fronteras concuerdan o no con los lindes de las naciones. Si no hay dirigentes, no habiendo estado, nadie puede plantearse si pertenecen o no a la misma nación que sentirse frustrado por no satisfacer las necesidades del principio nacionalista." NARANJO, p 86. "En sentido amplio, puede entenderse por Estado un conglomerado social, política y jurídicamente constituido, asentado sobre un territorio determinado, sometido a una autoridad que se ejerce a través de sus propios órganos, y cuya soberanía es reconocida por otros Estados." Entiéndase "nacionalización" como el proceso social e histórico mediante el cual se crea conciencia y sentido de identidad y pertenencia en el individuo sobre su vinculación con la Nación.
}

CONFUCIO: Padre de la nación más antigua del mundo 


\section{CULTURA MILENARIA}

Muchos historiadores hacen referencia a China como la nación más antigua del mundo, porque ha sufrido pocos cambios en sus estructuras desde el siglo VI a.C. hasta mediados del XX, cuando la revolución comunista materialmente destruyó una cultura de casi tres mil años. En cualquier caso, un gran número de tradiciones se han recuperado en las últimas décadas. (YAÑEZ, 2003: 5)

Podría decirse que existen regiones en China, especialmente al interior, que en ausencia de influencias externas, hoy permanecen detenidas en el tiempo. La forma de producción, alimentación, vestido, permanecen intactos. Aun así, los vientos transformadores que invitan a probar las bondades del desarrollo de las grandes ciudades, están llamando a gritos a los jóvenes campesinos en busca de oportunidades que los acerquen a los íconos de consumo de occidente, que comienzan a inundar el corazón de la tradicional nación.

China estuvo gobernada durante casi 4000 años por el "Hijo del Cielo" o Emperador. Vale mencionar que el "Reino del Centro" significado de los caracteres que forman la palabra China, (Zhong-Centro, Guo-País) propuso a su gobernante las funciones de mediar entre el Cielo y los hombres. El Dragón Celeste, tenía el mandato y con él la autoridad de celebrar ritos. La historia se divide en períodos dinásticos que llevan el nombre de la familia que gobernaba ese período, tal como las grandes familias reales de occidente. La dinastía XIA correspondió al período comprendido entre los siglos XXI a XVI a.C; la SHANG desde el XVI al XI a.c.; la ZHOU entre los siglos XI y 221 a.c., la QIN entre el año 221 al 206 a.c.; la HAN entre los años 206 a.c. a 220 d.c. Entre los siglos III a VI d.c. se presentaron algunas guerras internas y subdivisiones hasta que retomó la familia TANG asumiendo el poder dinástico entre los años 618 a 907; posteriormente la SONG hacia los años 970 a 1279; la YUAN entre 1279 y1368; la MING entre 1368 y 1644 y finalmente la QING O MANCHú; hacia 1644 hasta 1911.

Se podrían mencionar muchas cosas al respecto de cada dinastía, pero se consideraran solamente tres referentes:

1. Se hará mención a la dinastía reinante al momento de nacer Confucio (551-479 a.n.e), quien nació en el seno de una familia aristocrática venida a menos, en un período de caos y revolución social. La dinastía Zhou existía sólo de nombre, mientras sus estados vasallos no respondían al poder central, librando constantes guerras de poder, dejando al pueblo en la miseria. En este escenario transcurrió la infancia de Confucio, lo que motivó su búsqueda de un mundo de amor, armonía y orden. 
2. Se considerará al Príncipe Ying Zheng, heredero de la casa real de Qin, quien logró unificar China en el año 221 a.C. Precisamente con la ayuda de los míticos guerreros que pasaron a la historia por el descubrimiento, en 1974 de sus réplicas en terracota, en la ciudad de Xi'an; que fuera en algún momento capital del imperio. Después de vencer en una campaña de más de 15 años, en el llamado período de los reinos combatientes, se consolida la extensión territorial actual y finalmente, se hizo llamar Qin Shihuang que significa "primer soberano emperador", considerando que ya no era suficiente el título de rey. Aplicó el Código Qin en todos los reinos, unificando normas, sistemas de medición, moneda, escritura, construyó carreteras para el intercambio comercial y unió las murallas de los reinos para defenderse de los pueblos extranjeros, creando así una muralla de 6400 kilómetros de extensión, la Cháng Chéng, o “Larga fortaleza" conocida en Occidente como la Gran Muralla China. ${ }^{3}$

3. La dinastía Ching o Manchú que provenía de la zona norte, de Manchuria, fue la última dinastía con la cual se termina el imperio y se establece la República China, con la salida de Puyí el último de los Manchues en 1911. El período previo a la terminación de las dinastías, durante el siglo XIX, estuvo acompañado por la formación de Sociedades Secretas Xenófobas con ideas liberales y nacionalistas que conformaron el movimiento Kuomingtan cuyos pilares fueron el Nacionalismo (contra lo extranjero), Republicanismo (cambiar el Imperio) y Socialismo (reforma agraria). Su fundador fue Sun- Yat - Sen (1866-1925), considerado El Padre de la China Moderna, quien estudió medicina en Hong- Kong y posteriormente lideró la revolución de Nanjing en 1911, cuando cae Puyi, el último emperador, quien es apresado en la ciudad Prohibida.

\section{ESENCIA DE LA CULTURA CHINA}

Antes de hacer referencia a las propuestas de Confucio, se hará mención a la forma como se presentó el nacimiento de éste personaje. Todo está enmarcado en un mito que responde a unos hechos que transforman su condición humana, en una forma casi divina, que evidencia nuevamente una estrecha cercanía con el perennialismo, en virtud de la grandiosidad de su llegada al mundo.

Se retomará a YAÑEZ en su texto Confucio: "la sociedad china de aquellos tiempos se movía con base a unas rígidas tradiciones, en las que primaba el respeto a los mayores. Las mujeres siempre se hallaban supeditadas a su marido solo dormían a su lado si a él le apetecía; y llegaban a pasarse semanas enteras sin verle. Si bien no se quejaban, tampoco lo celebraban.

\footnotetext{
${ }^{3}$ http://www.museonacional.gov.co/guerreros1.html
} 
Se limitaban a vivir sometidas. A pesar de eso, Cheng Tsai tomó una iniciativa que debió provenir de una inspiración divina: al parecer la joven dio muestras de rebeldía al obedecer sus propios pensamientos. Temerosa de que por haberse casado con un hombre tan mayor no pudiera tener un hijo, decidió ir en secreto al tempo del monte Ni-Kieu.

Mientras ascendía por una de sus empinadas laderas, pudo advertir que las hojas de los árboles y de las plantas se erguían a su paso. Pronto fueron los troncos los que empezaron a inclinarse reverencialmente, a pesar de que el aire estuviese paralizado. Todo este prodigio se repitió después de que hubiera rezado para que se le concediese el don de engendrar a un varón. Aquella misma noche sus sueños resultaron muy inquietos, debido a que recibió la visita del Señor Negro (divinidad de las aguas) Nunca olvidaría el mensaje que éste le comunicó: "Traerás al mundo un hijo muy sabio en el interior de una morera hueca. Allí lo depositarás unos instantes"

No habían transcurrido nueve meses, cuando Cheng-Tai volvió a ser visitada mientras dormía. En este caso fueron cinco ancianos, a los que en seguida ella identificó como la representación humana de los cinco planetas más importantes del firmamento. Todos ellos tiraban de las riendas de una bestia mitológica, cuyo cuerpo era el de una vaca, sin embargo, se veía cubierta totalmente de grandes escamas y sólo disponía de un cuerno. En cierto momento la dejaron sola, con el propósito de que vomitase un objeto de jade, el cual ofrecía esta inscripción: "Un niño procedente del agua regenerará a la débil dinastía de los Cheu. Luego será considerado un rey sin corona". Cheng Tsai supo lo que debía hacer para corresponder a este obsequio: sin abrir los ojos, encontró la cinta de seda que debía atar en el cuerno de la bestia fantástica. Al momento toda la ensoñación desapareció. Como puede entenderse, se sintió tan inquieta que contó a su marido el sueño que acababa de tener. Te ha visitado el unicornio $k^{\prime} i$-lin y sus cinco señores respondió el viejo héroe, sin mostrar un gran asombro.

Cuando se aproximaba la fecha del parto, la jovencita ya había conseguido la suficiente información para saber que existía un lugar llamado la "morera hueca". De esta manera puedo marchar hasta la colina del Sur, donde pretendía encerrarse en una cueva que recibía ese nombre. Como era normal en aquellos tiempos, no dio este paso hasta contar con la aprobación de su marido. A partir de este momento volvemos a encontrarnos con la leyenda. Porque Cheng-Tsai no quiso que le acompañasen ninguna de sus doncellas; sin embargo, contó con la mejor ayuda espiritual: dos dragones montaron vigilancia a derecha y a izquierda de la colina; una pareja de espíritus femeninos de cuidaron de rociar el interior de la gruta con perfumes y brotó una fuente de agua en el suelo, aunque se secaría en el momento que fuese lavado el cuerpo del niño.

Como se puede entender la madre recogió al bebé con sus propias manos, debido a que salió sin encontrar ninguna resistencia y causar el menor dolor. Se supone que ella ni siquiera 
debió cortar el cordón umbilical. Después de haber aseado al pequeño, escuchó una música celestial y una voz que anunciaba esta recompensa: - Mujer, supiste conmover de tal manera al cielo, que se te ha concedido el honor de tener un hijo santo!

Este acontecimiento quedaría reflejado en el nombre del niño, ya que se le llamó Kong (cuyo significado es hueco) en honor de la cueva donde había nacido. Ahora conviene explicar que si le conocemos en occidente por Confucio, es porque así le denominaron los primeros monjes jesuitas que llegaron a China. Se ha situado este nacimiento el día 20 del décimo mes del reinado del Duque Siang de Lu, que equivale en nuestro calendario al 27 de agosto del 551 a. C. Una fecha algo discutible, pero que la mayoría acepta debido a ciertos testimonios arqueológicos" (Op Cit., YAÑEZ: 12-13).

\section{ALGUNAS DE SUS ENSEÑANZAS}

Las Analectas de Confucio son el registro de lo que Confucio y sus discípulos dijeron hace más de 2.000 años. Es un libro importante para el estudio de Confucio, su vida y pensamiento. El libro ha sido leído de manera obligatoria en la educación tradicional China. Sus líneas, frases, adagios se han convertido en lemas populares cotidianos, que dieron lugar en esencia a la civilización China antigua. Para entonces, tanto la existencia humana como la sociedad ideal se conseguían con la autocultivación de mente y cuerpo, la armonía familiar y la autoridad en el ejercicio del poder daban lugar a la pacificación del país. Como ya se mencionó, el período caótico del nacimiento de Confucio, motiva el hecho de que éste buscara un mundo de amor, armonía y orden.

Confucio aspiraba un mundo en donde los ancianos pudieran pasar sus últimos años en paz y felicidad, en el que se pudiera confiar en los semejantes como amigos cercanos, y todos los niños recibieran debidamente amor y educación. Un mundo ideal de prosperidad nacional, paz y riqueza universal y felicidad para el pueblo.

Viajó por muchos estados enseñando y aprendiendo. La moral y la jerarquía representaban el orden social apropiado, esencial para conseguir un mundo ideal. Para tal fin, debía existir un elemento común entre la moral y la ética popular; una conciencia primaria de "ren", o "benevolencia." Concepto que consideraba posible entre los hombres. Tal como Rousseau, años después, Confucio creía que todos los seres humanos nacían semejantes en naturaleza, con capacidad de ser benévolos aunque las diferencias se daban a partir de las influencias ideológicas y sociales del mundo.

"Ren" es la palabra más usada en los más de 10,000 caracteres de las Analectas de Confucio, pues se repite más de 100 veces. En muchas partes del libro, el filósofo expone el significado

CONFUCIO: Padre de la nación más antigua del mundo 
de la palabra. Cuando su estudiante Fan Chi preguntó qué era "ren," Confucio contestó: "Ama a tu prójimo". Mencio avanzó un poco más al respecto: "Ama a tu prójimo como a tu familia, y ama a todas las criaturas como si fueran seres humanos". Cuando el estudiante Zi Zhang preguntó cómo alcanzar "ren," Confucio contestó que a través de las cinco virtudes siguientes: dignidad, magnanimidad, honradez, laboriosidad y amabilidad. Con dignidad se gana el respeto ajeno; con magnanimidad, el apoyo de otros; con honradez, la confianza. Por otra parte, la laboriosidad ayudará a realzar la capacidad en el trabajo, y la amabilidad conducirá a la lealtad y fidelidad de los subordinados (HUO, 2006: 46).

"La autodisciplina y el respeto a las buenas costumbres equivalen al "ren". Si el ser humano es capaz de dominar sus deseos y ambiciones y enmarcarlos en los parámetros de la sociedad, el mundo sería un lugar benévolo. Los parámetros van más allá de la conducta, hacen referencia a un comportamiento comprometido con la sociedad".

\section{EL GOBIERNO COMO UN ARTE}

En el arte de gobernar de las analectas, se propone "Gobernar con benevolencia". El destino de un país y su pueblo está en manos de sus gobernantes. Confucio definió el significado de "gobierno" con su homónimo que significa "justicia". "Si usted gobierna con justicia, ¿quién se atreve a traicionarlo?"

Para Confucio lo más importante para el gobierno de un país es: "Suficiente suministro de alimentos, una fuerza militar adecuada y la confianza del pueblo". Este último punto resulta esencial para sostener un país. "Para un país o una familia, más terrible es el desequilibrio que la pobreza, y la inestabilidad más que la pequeñez. El equilibrio ahuyenta la pobreza; la armonía compensa la pequeñez; y la estabilidad niega el derrumbe".

\footnotetext{
Cuando el reino Lu encaró dificultades financieras, su rey procuró aumentar los impuestos al pueblo y pidió la opinión de Confucio. Uno de sus estudiantes contestó: "Si el pueblo viviera en la abundancia ¿Cómo podría el gobernante estar fuera de ella? Si el pueblo sufre escasez, cómo puede el gobernante alcanzar la abundancia?" Al decir esto, Confucio y sus estudiantes recomendaban al rey intentar enriquecer al pueblo como solución fundamental a las dificultades financieras, en lugar de trasladarle al pueblo los problemas.
}

Según DAWSON Raymond en su libro "Confucio" A los pocos años de la aparición del Ki-lin (unicornio), en el 479 a.C., Confucio se levantó muy pronto. Algo que a todos les pareció extraño. Después de realizar las abluciones oportunas y de vestirse, cogió su bastón y comenzó a pasear por delante de la puerta de su vivienda. De repente comenzó a cantar: 
"llegó el momento de que el Tai Chan se derrumbe

Pues el gran árbol será destruido.

¡El sabio desaparecerá cual planta marchita!" (DAWSON, 1968, 69)

\section{CONFUCIO TERMINÓ SIENDO CHINA}

"El duque de Ngau de Lu encargó que alrededor de la tumba de Confucio se edificara un templo funerario, en el que se reunieron todas las reliquias que lo recordaban: su bonete, sus trajes de los rituales, su laúd y su carro. En este pequeño conjunto surgió el culto confuciano. En el S. II a.c. el historiador Sse-ma Tsien escribió lo siguiente: Me sentí dominado por el respeto al entrar en la morada funeraria: viendo el carro del Maestro, sus ropas, sus objetos ceremoniales y todo lo que recordaba a los sabios que en las prescritas pepotas se dedicaban a instruir a sus semejantes. Tanta era mi emoción que me costó poder andar. En el mundo son legiones los que, desde los monarcas hasta los sabios, se vieron rodeados en su vida de la gloria; pero ésta terminó con sus propias vidas. Sin embargo, la de Confucio, aunque fuese un hombre vestido de lienzo, se ha transmitido durante diez generaciones. Los que se dedican al estudio le contemplan como a su patrón. Después del hijo del cielo y de los señores, todos los que en el reino del Antro hablan de las artes liberales, toman decisiones y regulan de acuerdo a las doctrinas del Maestro. Esto es lo que se debe entender como la verdadera santidad.

En el 194 a.c. el emperador Han, fundador de la nación China, llegó a la tumba de Confucio para inclinarse en señal de respeto. Una ceremonia que se repetiría a lo largo de dos mil años seguidos. Porque Confucio ya era China, el sabio prudente, el maestro de Lu, obtuvo pocos triunfos en vida, con su muerte se convirtió en el Ser Humano más famoso de su inmenso país. Todo se lo debió a la ciencia contenida en sus libros y al recuerdo de su siempre errante existencia.

La religión confuciana proviene de la antigua existencia de China, que se basaba en la adoración del universo en sus partes y en sus fenómenos. Este universalismo se dividió en las dos ramas del taoismo y el confucionismo. Como éste provenía de la antigüedad puede considerarse animista y politeísta. Sus divinidades surgen del yang y son espíritus benéficos, mientras que los demonios tienen su origen en el yin y son espíritus del mal como los espectros. Sin embargo, no pueden dañar al hombre sin la autorización del cielo. En esta doctrina el Cielo (t’ien) es el centro o el dios más alto, no hay otra deidad más allá del mundo, ni ningún creador de la vida o del universo. El hijo del cielo es el emperador (ti) cabeza al mismo tiempo de la religión estatal el cielo le dispensa su protección o le hace perecer cuando con su conducta se hace merecedor a ello". (DAWSON, 1968, 118)

CONFUCIO: Padre de la nación más antigua del mundo 


\section{MENTALIDAD COLECTIVA}

El tamaño de China, su larga historia, su diversidad regional y su estructura jerárquica hacen que sea en la actualidad altamente compleja; es difícil hablar de una sola sociedad China o definir los desafíos del desarrollo desde la óptica de Occidente. Hay todavía mucha mentalidad feudal dentro de la sociedad y la economía, y es a través de la conciencia colectiva que el individuo-económico es todavía una minoría comparado con el individuo-feudal. (LIU, 2004)

La mayoría de los chinos no actúan en su propio interés individual, una condición necesaria para el funcionamiento normal de la economía capitalista de mercado. Esto explica por qué las más exitosas empresas chinas modernas están organizadas a lo largo de líneas familiares, una especie de socialismo feudal. En ese sentido, el confucionismo es lo contrario al proyecto socialista en la medida en que el porvenir colectivo se pierde en su esencia. El confucionismo esta en todas partes, en las mínimas actitudes, en el respeto a una etiqueta omnipresente. Ha sido eficaz, de hecho, el confucionismo influenció en gran medida el sudeste asiático contribuyendo al progreso en Singapur, Taiwán, Macao y Hong Kong, gracias a la presencia de la diáspora China. (MANDELBAUN, HABER, 2005, 55)

El Partido Comunista Chino, puede ser entendido como una institución feudal. La mayoría de los chinos, todavía actúa sobre una mentalidad colectiva en el sentido socialista feudal. Así la democracia occidental no resulta oportuna en estas sociedades. (Op Cit, LIU)

El confucionismo se ha adaptado a la modernidad, a pesar de ser una tradición más oral que escrita, ha logrado pasar las generaciones a partir del ejemplo. Con facilidad, los jóvenes chinos no saben acerca de las analectas de Confucio, pero practican la piedad filial como si leyeran los cuatro libros clásicos. "Se presume que quien es buen hijo y buen hermano, será buen ciudadano y buen súbdito" (VILLAR, 2006, 20)

Las enseñanzas de Confucio se reflejan aún en la actitud de la gente, aunque probablemente un joven transeúnte no sepa quién fue, sí reconoce en el ejemplo de sus padres y abuelos, su legado y lo practica en su cotidianidad. A pesar de ello, los comentarios de los jóvenes Chinos que regresan después de estudiar fuera de su país, tienen que ver con ideas nuevas, relacionadas con la búsqueda de su enriquecimiento personal, al mejor estilo del liberalismo clásico (ROJAS, 2006, 39).

Las virtudes que promueve el confucionismo son el respeto a los demás, la lealtad, la virtud, la motivación, la solidaridad, la educación, la comunicación de los saberes, que armonizan completamente con la sociedad actual, con el espíritu de empresa, con la sociedad contemporánea. El fracaso de Mao estaba escrito dada la solidez y la presencia de esta 
tradición multisecular en el corazón de todos y cada uno de los chinos y el fracaso económico debía conducir al fracaso político a la sombra del gran líder. Deng Xiao Ping aguardaba el momento de proponer otra política diferente. (Op Cit, MANDELBAUN).

La apertura de Deng fue total, se presenta el fin de la colectivización agrícola, se da un llamado a los capitalistas extranjeros y un retorno de la jerarquía natural propuesta por Confucio. Sin embargo, esa apertura masiva y rápida conlleva un peligro potencial, para los chinos de la diáspora, al tiempo que aportaban su dinero, no reintroducirían la tradición budista confucionista, en una China que había perdido sus referencias, al mismo tiempo, los chinos exiliados habían conocido otras costumbres en occidente, portador de valores diferentes cuando, no contrarios. En efecto los chinos de la diáspora invitados por Deng eran portadores de dos tradiciones rechazadas por la China socialista, la propia, mantenida al abrigo de ataques y conservada como cosa preciosa y la occidental, combinación del individualismo con la democracia, forjada tras varios siglos de maduración y algunas revoluciones en medio. (Ibid )

Cada individuo es el producto de dos factores: la herencia y la educación. La primera tiende a proveerle de los órganos y las funciones mentales que le transmiten las generaciones precedentes; la segunda es el resultado de las múltiples influencias del medio social en que el individuo está obligado a vivir. Esta acción educativa es, por consiguiente, una adaptación de las tendencias hereditarias a la mentalidad colectiva: una continua aclimatación del individuo en la sociedad. (INGENIEROS, 2005)

En ese sentido, vale mencionar la obra de HALBWACHS "Les Cadres Sociaux de la Mémoire", en la que, ofrecía una perspectiva sociológica sobre la cuestión de la memoria. Recoge por un lado una serie de consideraciones sobre los elementos sociales de la memoria y, por otro, analiza los procedimientos de memorización colectiva de la familia, los grupos religiosos y las clases sociales. La conclusión fundamental de esta investigación es que, existen unos "marcos sociales de la memoria", bien generales como el espacio, el tiempo y el lenguaje; bien específicos, relativos a los diferentes grupos sociales, que crean un sistema global de pasado que permite la rememorización individual y colectiva. Para Halbwachs, los ámbitos colectivos más relevantes implicados en la construcción de la memoria son la familia, la religión y la clase social. Así, los individuos articulan su memoria en función de su pertenencia a una familia, una religión o una clase social determinada.( HALBWACHS, 1994, 38)

En cuanto a la familia, el marco colectivo se ordena según un criterio genealógico que permite la reconstrucción de una memoria familiar en la que está incluido el individuo. El medio mnemotécnico fundamental que utiliza la familia es el nombre de pila que, por un lado, reenvía al individuo aludido, en su frecuente repetición, a la trama genealógica y, por otro lado, instala la imagen de una persona particular: "Cuando pienso, por ejemplo, en el 
nombre de mi hermano, uso un signo material que, por sí mismo, es significativo ( . . . ) El signo material en tanto que tal juega un papel accesorio: lo esencial es que mi pensamiento concuerda entonces con los que, en el espíritu de mis padres, representan a mi hermano: el nombre no es sino el símbolo de esta concordancia ( . . . ) Es decir que mi pensamiento es entonces singularmente rico y complejo, ya que es el pensamiento de un grupo en cuyas dimensiones, por un momento, se prolonga mi conciencia" (HALBWACHS, 2004)

Cuando los chinos conservadores Ilamaban a rechazar la "gangrena occidental", iba implícita una crítica contra el reformador Deng y su séquito de seguidores. La astucia de éstos fue demostrar mediante pacientes y bien logrados experimentos, que el socialismo chino era capaz de integrar ciertos elementos del capitalismo occidental y que estos elementos podrían proferir mayor eficacia al régimen en evolución y consolidarlo a fin de cuentas. Deng incluso logró que el confucionismo recuperado, defendiese el sistema chino frente a la influencia perniciosa del exterior así como los japoneses de la era meiji se protegieron con su tradición confucionista, sintoista, proponiendo una barrera contra la occidentalización demasiado profunda de su sociedad, que ellos deseaban fuese única. También se convirtió el confucionismo recuperado en elemento de dinamización de China. (Op Cit. MANDELBAUN)

Vale rescatar la tolerancia China y en general de Asia oriental frente a las palabras nuevas y su capacidad para lograr que coexistan sin violencia con las creencias anteriores. Por supuesto, teniendo en cuenta, la ausencia de una religión revelada y la importancia concedida al equilibrio, al camino medio, a la armonía de las relaciones y a las búsquedas del consenso, fue más fácil que China mantuviera como propone Halbwachs, su memoria colectiva, pero, al mismo tiempo, aprovechara la llegada de los nuevos vientos occidentales del capitalismo.

En Oriente el concepto de verdad absoluta carece de sentido, solo cuentan las percepciones de la realidad, diferentes, divergentes o tal vez opuestas, y por tanto, la necesidad de negociar opiniones al rededor de una realidad aceptable para todos, que pasará a ser la realidad en consecuencia; nada más lejano a la pretensión occidental de poseer la verdad absoluta, de donde resulta que si uno tiene razón el otro esta sumido en el error. (Ibid)

China ha logrado asimilar las propuestas de occidente, como le correspondiera al Japón del emperador Meiji luego de la visita del comodoro Perry, sin dejar atrás los recuerdos colectivos representados en las acciones de su gente. Su capacidad para asumir conceptos nuevos sin rechazar los valores del pasado, combinando las herramientas técnicas de occidente con su proyecto de país socialista.

La sociedad China es conciente de la entrada de las nuevas olas de Occidente, pero sigue confiando en que las enseñanzas del pasado y el ejemplo de las tradiciones servirán para 
recibir los beneficios de la fuga de cerebros, en la medida en que, a su regreso sus aportes, seguramente representarán una proporción mayor en competitividad y productividad, que si se hubiesen quedado esperando por algún cupo en las universidades.

\section{PARA CONCLUIR}

Confucio es considerado creador de la religión de Li, que buscaba un orden social ideal basado en el amor al prójimo y el respeto a la autoridad cuyos símbolos deben ser los ritos sociales del culto público y las festividades en el ritual y la música. El Li de Confucio al igual que las leyes de Moisés, abarca leyes religiosas y de la vida civil, y las considera partes integrantes de un todo. Confucio era producto de su tiempo, vivía en lo que Comte llamó la era religiosa. (LI, 1952: 24) El confucionismo dio una especie de significado filosófico y hasta político al ritual, a la música y la danza. Los estudios de su época eran: ritual, música, tiro de ballesta, conducción de carruajes, escritura y matemática.

Pero al ver en la actualidad la revitalización de China, no debería entenderse como en los siglos atrás cuando China era la potencia dominante Asia oriental. El pueblo chino puede estar orgulloso de su proceso de revitalización, pero al parecer, no debería tener ningún sentimiento de "nacionalismo histórico".

El resurgimiento de China es un concepto occidental para describir su desarrollo. Ya lo mencionaba Napoleón al hacer referencia al "gigante dormido". La mayoría de las potencias se basaron en el imperialismo para explotar ilimitadamente al nuevo continente. El progreso de China se basa en cinco mil años de historia y la asimilación de su construcción de nación. La China moderna es una nación que participa en el desarrollo del mundo.

El pueblo chino tiene un fuerte sentido de la historia, que puede ser tanto un tesoro como una carga. Es un tesoro porque siempre puede tener un ejemplo histórico para identificarse y tener un punto de vista histórico de la misión nacional y el auge y caída del Estado. Puede ser una carga porque está acostumbrado a ser fuerte. Esta perspectiva representa una misión histórica en donde China debería ser fuerte y poderosa, cualquier debilidad o humillación es temporaria y cada persona China debería esforzarse en seguir el esplendor del pasado ${ }^{4}$.

Confucio, tiene suficientes méritos para ser reconocido como el padre del pensamiento chino y por que no, de Asia oriental, sin desconocer la influencia notable del Budismo en China y tampoco las propuestas, menos pragmáticas de Lao Tse. En la búsqueda de la armonía indi-

\footnotetext{
${ }^{4}$ Pueblo en Línea, en: http://spanish.peopledaily.com.cn//31619/4536406.html, junio 27 de 2006
} 
vidual, familiar y social; Confucio ofrece el ejemplo que se ha mantenido generacionalmente hasta nuestros días, sin dejar de lado que sus enseñanzas datan de cientos de años atrás, es innegable la fuerza de su discurso, que se nutre a diario con las actitudes del pueblo chino. La mística de las tradiciones, el encanto enigmático de sus rituales corresponden a un pueblo que a pesar del paso del tiempo, permanece, evoluciona y se transforma buscando una relación armónica entre los suyos.

\section{BIBLIOGRAFÍA}

BERGUA, Juan. Confucio y Mencio

CARMODY, Jhon. Los grandes maestros de la humanidad: Buda, Confucio, Jesús y Mahoma

CAUDET, Francisco. Confucianismo

CLEARY, Thomas. Confucio: El arte de ser humano

CONFUCIO, Los Cuatro Libros, Ed. Alfaguara

- - - - -, Tratados Morales y Políticos

DAWSON Raymond, "Confucio", Oxford: Clarendon Press, 1968, Oxford.

DO DINH Pierre: Confucio y el Humanismo Chino

FRANKE, Herbert y TRUZETTEL, Rolf: El imperio Chino

GARCIA, Victor. La sabiduría oriental: Taoísmo, Budismo, Confucianismo

GELLNER, Ernest. Naciones y Nacionalismos, Alianza Editorial, 1994, Madrid.

GUERRERO, Marcelino. Confucio

HALBWACHS Maurice, Idem Supra, Anthropos, 2004, Barcelona. Les Cadres Sociaux de la Mémoire, Ed. Albin Michel, 1994, Paris.

HITLER, Adolf. Mi Lucha, Editorial Solar Cía. S. en C., 2002, Bogotá. Traducción de Alberto Saldivar P. 
HOBSBAWM, Eric. Naciones y nacionalismos desde 1780, Crítica, 2000, Barcelona.

http://www.museonacional.gov.co/guerreros1.html

HUO, Jianying. El sabio Confucio y sus analectas, en: http://www.chinatoday.com.cn/hoy/2006n/ s2006n12/p46.html

INGENIEROS José, El Hombre Mediocre, Panamericana Editorial, 1993, Bogotá (impresión de 2005).

LI, Yutang. La Sabiduría de Confucio, Siglo XX, 1952, Buenos Aires.

LESLIE, Daniel. Confucio

LIU Henry CK, traducción de Fernández Julio, Visiones contradictorias sobre China, Julio de 2004. en: http://archives.econ.utah.edu/archives/reconquista-popular/2005w29/msg00219.htm

MANDELBAUN Jean, HABER Daniel, China la Trampa de la Globalización, Urano Tendencias, 2005, Barcelona.

MORIN Edgar, El Estado-Nación, en: Teorías del Nacionalismo, Paidos, 1993, Barcelona.

NARANJO, Vladimiro. Teoría Constitucional e Instituciones Políticas, Temis, Octava Edición, 2000, Bogota.

Pueblo en Línea, en: http://spanish.peopledaily.com.cn//31619/4536406.html, junio 27 de 2006

RENAN Ernest, Qu'est-ce qu 'une nation ? Calmann-Levy, 1882, Paris.

ROJAS Héctor, De regreso de China, en: Revista Amigos de China, Edición No 5, Octubre 2006, Bogotá.

La familia: Institución dinámica, soporte de los cambios en China, en: Revista Vox Populi, N. 3, Escuela de Finanzas y Estudios Internacionales FUSM, Octubre 2004, Bogotá.

SMITH, Anthony. La Identidad Nacional, Trama Editorial, 1997, Madrid.

¿Gastronomía o geología? El papel del nacionalismo en la reconstrucción de las naciones, en: Zona Abierta, n. ${ }^{\circ} 79$.

CONFUCIO: Padre de la nación más antigua del mundo 
Nacionalismo, Alianza, Madrid, 2004.

TEOTOPOULOS, O. Confucio

VILLAR Borda Luis, Vida y Obra de Confucio, en: Revista Amigos de China, Edición No 5, Bogotá, Octubre 2006.

WILHELM, Richard. Confucio

WOLPIN, Samuel. La filosofía China según Confucio y Lao Tsé.

YAÑEZ Manuel, Confucio, EDITORS SA, 2003, España. 